ANNUAL OF NAVIGATION 19/2012/part 2

10.2478/v10367-012-0024-6

ADAM WEINTRIT, PIOTR KOPACZ

Gdynia Maritime University

ANDRZEJ BĄK, JANUSZ URIASZ

Maritime University of Szczecin

KRZYSZTOF NAUS

Polish Naval Academy

\title{
POLISH APPROACH \\ TO THE IMO MODEL COURSE 1.27 \\ ON OPERATIONAL USE OF ECDIS
}

\begin{abstract}
In consequence of the adoption of the Manila Amendments to the STCW Convention and Code, the ECDIS model course would need to be reviewed and updated. Accordingly, three Polish matitime academies/universities present common position what necessary steps should be taken to revise and update existing IMO model course on Operational Use of ECDIS. Notes and comments relate to both the current existing IMO model course 1.27 on operational use of ECDIS and its new version proposed by the United States in the document STW 43/3/1. Comments and remarks to revised draft model course 1.27 cover the following parts and topics: Course Framework, Course Outline and Timetable, Detailed Teaching Syllabus, Instructor Manual, Evaluation and Assessment, and appendices for the ECDIS Instructor: Introduction of Operational use of ECDIS, ECDIS Performance Standard references, ECDIS Carriage Requirements, STCW Manila Amendments on ECDIS, Training scenario types and scenario success, and Integrated navigation training example.
\end{abstract}

\section{Keywords:}

Manila Amendments, STCW, ECDIS model course.

\section{INTRODUCTION}

The ECDIS will be one of the most important navigation and decision support tools available to the navigator and that the complexity of this equipment should be recognized and understood. The ability of a watchkeeping officer to be competent and confident in operating the ECDIS equipment is essential for safety, security and the protection of the marine environment. 
This paper comments on IMO Model Course 1.27, as well as the document STW 43/3/1 and provides remarks on the revised draft model course on the operational use of Electronic Chart Display and Information Systems (ECDIS) [10].

\section{PURPOSE OF THE MODEL COURSES}

The purpose of the IMO model courses is to assist maritime training institutes and their teaching staff in organizing and introducing new training courses, or in enhancing, updating or supplementing existing training material where the quality and effectiveness of the training courses may thereby be improved.

It is not the intention of the model course program to present instructors with a rigid 'teaching package' which they are expected to 'follow blindly'. Nor is it the intention to substitute audio-visual or 'programmed' material for the instructor's presence. As in all training endeavors, the knowledge, skills and dedication of the instructor are the key components in the transfer of knowledge and skills to those being trained through IMO model course material. Because educational systems and the cultural backgrounds of trainees in maritime subjects vary considerably from country to country, the model course material has been designed to identify the basic entry requirements and trainee target group for each course in universally applicable terms, and to specify clearly the technical content and levels of knowledge and skill necessary to meet the intent of IMO conventions and related recommendations.

\section{POLISH INTERNATIONAL ACTIVITIES ON ECDIS}

In last 20 years Poland was very active on IMO forum on the field of ECDIS standardization:

1. Performance Standards for ECDIS - 1995.

2. IMO Model Course on Operational Use of ECDIS - [5].

3. Interim Guidance on Training in the Use of ECDIS - $[6,8]$.

4. IAMU Model Course on ECDIS - 2004.

5. Performance Standards for ECDIS - 2006.

6. An Operational Handbook on ECDIS - 2009 [11].

7. STCW Convention, Manila - 2010.

8. IMO Model Course on Operational Use of ECDIS - [10]. 
In Chapter II, part A Mandatory standards regarding provisions of the annex to the Convention of STCW Code titled Standards regarding the master and deck department in section A-II/1 Mandatory minimum requirements for certification of officers in charge of a navigational watch on ships of 500 gross tonnage or more in table A-II/1 titled Specification of minimum standard of competence for officers in charge of a navigational watch on ships of 500 gross tonnage or more in column 2 titled Knowledge, understanding and proficiency for part titled Plan and conduct a passage and determine position there is the following Note [2]:

ECDIS systems are considered to be included under the term 'charts'.

In the revised STCW Convention and Code adopted at the Diplomatic Conference of Parties to the International Convention on Standards of Training, Certification and Watchkeeping for Seafarers helt in Manila from 21 to 25 June 2010 under the auspices of the International Maritime Organization (IMO) in Part B - Recommended Guidance Regarding Provisions of the STCW Convention and Its Annex, Section B-I/12 Guidance regarding the use of simulators was included full text (whole 12 pages) of Interim Guidance on Training and Assessment in the Operational Use of the Electronic Chart Display and Information System (ECDIS) Simulators [8].

\section{MANILA AMENDMENTS TO THE STCW CONVENTION AND CODE}

Conventions are modified from time to time to cope up with the new technologies, stringent environment and safety policies and for improvement in the current system. On the same line, the STCW 95 convention was amended ensuring that the global needs for safety and environment policy and standard of training and certification to operate the advanced technology in coming future are achieved.

In June 2010 significant changes to the STCW (Standards of Training, Certification and Watchkeeping for seafarers) Convention and Code were agreed at an IMO Diplomatic Conference in Manila in order to bring the Convention and Code up to date with new developments. These changes, known as 'he Manila amendments to the STCW Convention and Code'are due to enter into force on 1 January 2012 and are the first major revisions since the Convention and Code were updated in 1995.

The IMO has advised that amongst the amendments adopted, the important changes include: 
- improved measures to prevent fraudulent practices associated with certificates of competency and strengthen the evaluation process (monitoring of Parties' compliance with the Convention);

- revised requirements on hours of work and rest and new requirements for the prevention of drug and alcohol abuse, as well as updated standards relation to medical fitness standards for seafarers;

- new certification requirements for able seafarers;

- new requirements for marine environment awareness training and training in leadership and teamwork;

- new training and certification requirements for electro-technical officers;

- updating of competence requirements for personnel serving on board all types of tankers, including new requirements for personnel serving on liquefied gas tankers;

- new requirements for security training, as well as provisions to ensure that seafarers are properly trained to cope if their ship comes under attack by pirates;

- introduction of modern training methodology including distance learning and web-based learning;

- new training guidance for personnel serving on board ships operating in polar waters;

— new training guidance for personnel operating Dynamic Positioning Systems;

- new requirements relating to training in modern technology such as electronic charts and information systems (ECDIS).

The Manila Amendments to the STCW Convention and Code entered into force on 1 January 2012. In accordance with these regulations, ALL deck officers assigned to serve on vessels that are fitted with Electronic Chart Display and Information Systems (ECDIS) must receive approved training in the use and limitations of ECDIS.

\section{MANDATORY CARRIAGE OF ECDIS}

Mandatory carriage of ECDIS, the biggest change in navigational practice since the introduction of radar or GPS, or Mercator chart in the past, has just begun. From 1 July, 2012 onwards to 1 July, 2018 all IMO vessels over 10,000 GT are requested to install and operate ECDIS. Vessels may be exempt from this obligatory carriage of ECDIS if they are taken out of operation in less than two years after the implementation date. 


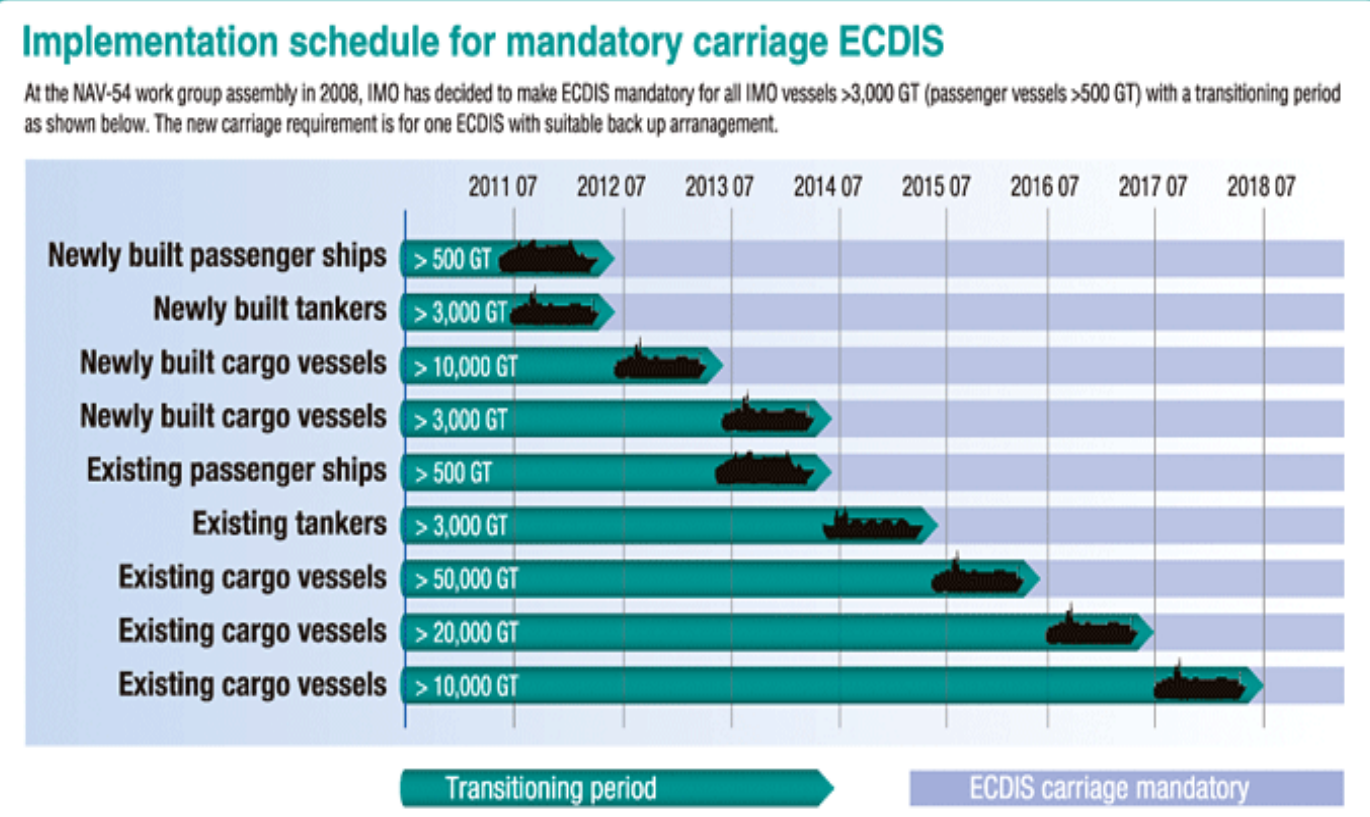

Fig. 1. Implementation schedule for mandatory carriage of ECDIS [12]

\section{NEW REVISED VERSION OF IMO MODEL COURSE 1.27 ON OPERATIONAL USE OF ECDIS}

In 2010 new version of model course on the operational use of Electronic Chart Display and Information Systems (ECDIS), developed by the United States Merchant Marine Academy, Kings Point, New York was publish as final revised draft model course set out in the annex of document [9].

American document is divided into 5 parts:

- Part A: Course Framework;

- Part B: Course Outline and Timetable;

- Part C: Detailed Teaching Syllabus;

- Part D: Instructor Manual;

- Part E: Evaluation and assessment. 
Table 1. ECDIS Course Timetable [9]

- Course Timetable $\mathbf{-} \mathbf{5}$ days, $\mathbf{4 0 . 0}$ hours minimum

\begin{tabular}{|c|c|c|c|c|}
\hline $\begin{array}{l}\text { Period } \\
\text { Day }\end{array}$ & 1st Period (2.0 hours) & 2nd Period (1.5 hours) & 3rd Period (2.0 hours) & 4th Period (2.5 hours) \\
\hline Day 1 & $\begin{array}{l}\text { Elements of ECDIS } \\
\text { 1. Course introduction \& } \\
\text { familiarization plan } \\
\text { 2. Purpose of ECDIS } \\
\text { 3. Value to navigation } \\
\text { 4. } \text { Correct \& incorrect use }\end{array}$ & $\begin{array}{ll}\text { 5. } & \text { Work station start, stop \& } \\
\text { layout } \\
\text { 6. Vessel position } \\
\text { 7. Position source }\end{array}$ & $\begin{array}{l}\text { 8. Basic navigation } \\
\text { 9. Heading \& drift vectors } \\
\text { 10. Understanding chart data }\end{array}$ & $\begin{array}{l}\text { Ex.1 Simulator exercise - } \\
\text { open sea (basic integrated } \\
\text { navigation) }\end{array}$ \\
\hline Day 2 & $\begin{array}{l}\text { 11. Chart quality \& accuracy } \\
\text { 12. Chart organization } \\
\text { Watchstanding with } \\
\text { ECDIS } \\
\text { 13. Sensors } \\
\text { 14. Ports \& data feeds }\end{array}$ & $\begin{array}{l}\text { 15. Chart selection } \\
\text { 16. Chart information }\end{array}$ & $\begin{array}{l}\text { 17. Changing the settings } \\
\text { 18. Chart scaling } \\
\text { 19. Information layers }\end{array}$ & $\begin{array}{l}\text { Ex.2 Simulator exercise - } \\
\text { coastal waters (chart display } \\
\text { settings) }\end{array}$ \\
\hline Day 3 & $\begin{array}{l}\text { 20. System \& position alarms } \\
\text { 21. Depth \& contour alarms }\end{array}$ & $\begin{array}{l}\text { ECDIS Route Planning } \\
\text { 22. Vessel maneuvering } \\
\text { characteristics } \\
\text { 23. Route planning by table }\end{array}$ & $\begin{array}{l}\text { 24. Route planning by chart } \\
\text { 25. Track limits } \\
\text { 26. Checking plan for safety }\end{array}$ & $\begin{array}{l}\text { Ex. } 3 \text { Simulator exercise - } \\
\text { coastal \& confined waters } \\
\text { (navigation alarms \& route } \\
\text { scheduling) }\end{array}$ \\
\hline Day 4 & $\begin{array}{l}\text { 27. Embedded tide, current \& } \\
\text { climate almanac } \\
\text { 28. Route schedule } \\
\text { 29. User charts in route } \\
\text { planning }\end{array}$ & $\begin{array}{l}\text { ECDIS Targets, Charts \& } \\
\text { System } \\
\text { 30. ARPA tracked target } \\
\text { overlay } \\
\text { 31. AIS functions } \\
\text { 32. Radar overlay (RIB) } \\
\text { functions }\end{array}$ & $\begin{array}{l}\text { 33. Procuring \& installing } \\
\text { chart data } \\
\text { 34. Installing chart } \\
\text { corrections }\end{array}$ & $\begin{array}{l}\text { Ex.4 Simulator exercise - } \\
\text { confined waters (advanced } \\
\text { integrated navigation with } \\
\text { ECDIS) }\end{array}$ \\
\hline Day 5 & $\begin{array}{l}\text { 35. System reset \& backup } \\
\text { 36. Archiving with ECDIS } \\
\text { data management utility } \\
\text { 37. Data logging and logbook } \\
\text { 38. Playback }\end{array}$ & $\begin{array}{l}\text { ECDIS Responsibility \& } \\
\text { Assessment } \\
\text { 39. Responsibility }\end{array}$ & $\begin{array}{l}\text { 40. Effective navigation with } \\
\text { ECDIS } \\
\text { Ev.1 Written evaluation }\end{array}$ & $\begin{array}{l}\text { Ev.2 Simulator exercise - } \\
\text { coastal \& confined waters } \\
\text { (underway ECDIS navigation } \\
\text { assessment) }\end{array}$ \\
\hline
\end{tabular}

\section{MAIN QUESTIONS}

There are the following main questions on the model course organization:

Question 1: $\quad$ How many days?

Answer: $\quad 5$ days

Question 2: How many hours?

Answer: 40 hours
Lectures
10 Hours
Demonstrations 10 Hours
Exercises 20 Hours
+2 Hrs Exam

Question 3: $\quad$ How many trainees per workstation?

Answer: $\quad 1$ trainee [2 trainees] 
Question 4: How many instructors per laboratory/classroom?

Answer: When a class size exceeds 12 trainees, an assistant instructor is required

Question 5: What qualifications for instructor/ass. Instructor?

Answer: ??? Good question!!!

Master Mariner?

Academic level?

And what about ECDIS experience?

Question 6: What are the requirements for ECDIS type specific model course? Answer: ??? Another very good question!!!

The responsibility for the implementation of specific ECDIS training is by the company

\section{ECDIS INSTRUCTOR QUALIFICATIONS}

The following are the minimum qualifications recommended for instructors delivering a course that follows the IMO Model Course 1.27. The instructor in charge should:

- preferably hold an STCW Masters certificate of competency with other certification subject to the approval of the Administration;

- have successfully completed an IMO ECDIS model course;

- have type specific training, preferable from the manufacturer, of the ECDIS system used for training;

- have a detailed knowledge of the requirements of SOLAS chapters V/2, V/19, and $\mathrm{V} / 27-20$, as amended;

- have an up-to-date knowledge of the ECDIS Performance Standards currently in force and knowledge of relevant STCW requirements and guidance;

- be fully aware of current ENC data transfer standards and presentation libraries of the IHO, methods of ENC licensing and updating and current IMO recommendations on ECDIS software and other issues;

- be familiar with the current ECDIS equipment and installation requirements of the IEC;

- have a current relevant teaching qualification or successfully completed a Train-The-Trainer course, preferably including the application of simulators in training. 


\section{INDUSTRY RECOMMENDATIONS FOR ECDIS TRAINING}

'Best Practice ECDIS Training Guidance' makes several recommendations for ECDIS training and underlines the importance of all navigating officers being appropriately trained and familiarized on the ship's ECDIS. Being aware that the implementation of Electronic Chart Display and Information Systems (ECDIS) has given rise to confusion in regard to ECDIS training, an industry group, organised and coordinated by The Nautical Institute and comprising leading international shipping industry organisations, held a series of meetings in order to produce this guidance on issues of training and competency for ECDIS.

The 2010 amendments to the STCW Convention for ECDIS training will not take full effect until 2017. Therefore in accordance with best practice it is recommended that approved ECDIS training be undertaken as soon as practical to ensure that all bridge watchkeeping officers meet all the competencies required by STCW prior to sailing on a ship fitted with ECDIS. It is recognised by all signatories to this guidance that ECDIS, as defined by the International Maritime Organization (IMO), when implemented will be one of the most important navigation and decision support tools. The complexity of ECDIS should be recognised and the ability of a watchkeeping officer to be competent and confident in operating ECDIS as part of the shipboard navigational system is essential for safety, security and protection of the marine environment. The regulatory requirements for Generic Training and Familiarisation in ECDIS are covered by various international instruments including the IMO STCW Convention, the ISM Code, SOLAS and also by national laws. The industry also recognises that compliance with these regulations including the required competencies are increasingly being examined by external parties including Port State Control, insurance inspectors, charterers and accident investigators. The industry organisations recognise the following definitions for ECDIS Training.

\section{ECDIS TRAINING DEFINITIONS}

Generic ECDIS Training: ECDIS training to ensure that navigators can use and understand ECDIS in the context of navigation and can demonstrate all competencies contained in and implied by STCW 2010. Such training should ensure that the navigator learns to use ECDIS and can apply it in all aspects of navigation, including the knowledge, understanding and proficiency to transfer that skill to the particular ECDIS system(s) actually encountered on board, prior to taking over 
navigational duties. This level of training should deliver the competencies at least equivalent to those given in IMO Model Course 1.27.

Familiarisation: Following the successful demonstration of competencies contained in the Generic ECDIS Training, familiarisation is the process required to become familiar with any onboard ECDIS (including backup) in order to assure and demonstrate competency onboard any specific ship's ECDIS installation, prior to taking charge of a navigational watch.

\section{POLISH PROPOSALS AND COMMENTS}

According to Polish Working Group ander chairmanship of Adam Weintrit the following remarks to Parts A and B of the revised draft model course 1.27 [9] should be considered and discussed.

\section{Part A: Course Framework}

\section{Scope}

The required use of a complete type-approved ECDIS with numerous chart formats installed seems to be an overspecification.

\section{Course intake limitations}

Class size should be limited to 1 trainee [2 trainees] per ECDIS workstation. For example, where a classroom training environment has 8 ECDIS workstations, the maximum class size is 8 trainees [16 trainees].

When a class size exceeds 12 trainees, an assistant instructor is required in both settings, qualified to the satisfaction of the lead instructor - the requirements for assistant instructor should be defined.

\section{Staff requirements}

At least one person of the instructors' team should hold a Master License (certificate of competency, issued by IMO white list flag state).

The instructor in charge should: have successful completion of Train-The-Trainer course, or equivalent preferably including the application of simulators in training.

\section{Teaching Facilities and equipment}

Teaching facilities and equipment should be described by functions, simulating capabilities etc. 
Full mission simulator is not necessary to perform ECDIS course. The crucial is official type-approved ECDIS application, not the vessel simulator itself. Two different classrooms are not necessary. Lectures and exercises can be performed in one classroom equipped with adequate visualization devices connected to instructor's and user's computers via video splitter. Links in model course to existing manuals, manufacturers specifications or recommendations shall be removed as they are changeable in time.

The requirements that each Bridge should be fitted for plotting on standard paper charts, as well as VHF radio, either type-approved and de-amplified, or digitally embedded in the simulation software are unnecessary because it is assumed that trainees undertaking this course have accomplished some formal instruction in Terrestrial Navigation, have at minimum some familiarization with visual navigation, have accomplished a period of supervised bridge watch-keeping duties... (Entry Standards).

Too short list of navigational equipment interacting with ECDIS has been presented in that chapter. It is suggested to broaden it with: echo sounder, log, gyrocompass, NAVTEX, AIS (of class A), LRIT, and other. Such a modification should allow conducting training on the ECDIS broadened functionalities.

Lecturing without demonstration is conducted in the same ECDIS classroom with the workstations powered down - it is not necessary to lecture in the same classroom.

\section{Simulation Lab}

Trainee station do not have to consist of four PCs. This should depend on the capabilities and technology solutions of specific symulator producers. Also VHF radio is completely out of place. The trainee should focus on ECDIS operations only, and some other tasks may be confusing and distract the user.

Instead of operating/providing bridge simulator on trainee workstation the NMEA signal can be simulated as a raw signal directly to ECDIS application.

\section{Simulation software}

The sentence: Assessment and evaluation systems built into the simulation software... - it is from Transas type specification - should be removed.

\section{Recommended ECDIS simulation performance standards}

ECDIS is an integrating device, and its use should be mastered in solo watchstanding. It follows that ECDIS simulation should suit solo watchstanding training, and this certainly demands the inclusion of the visual scene at all times, but 
on the other hand the ECDIS simulator is not a game, the visual scene should be treated as additional option.

Some mentioned points are not required, and should be removed from the list:

5) provide VHF communications between all ownships and instructor - this is not GMDSS course;

7) $360^{\circ}$ up $\&$ down visualization should be treated as optional;

9) permit simultaneous navigation on paper charts associated with area databases as appropriate to ECDIS watchstanding;

10) provide adequate and well-lit surface for plotting on paper charts as the required means of backup required for single ECDIS installation.

Practical methods of communication and plotting on paper chart should not be part of ECDIS model course. It increases the cost of a simulator (additional software and hardware do not offer anything new). The trainee taking part in ECDIS course is already familiarized with radio communication and paper charts. The recommended course should mainly focus on practical use of ECDIS.

\section{Optimal ECDIS classroom}

Wording taken directly from Transas software description. Should be deleted entirely and replaced with general description or should be treated as example only.

Due to the variety of different ECDIS software products and their possible configuration and data-simulation opportunities within an ECDIS training environment, there should be preference for an independent description of 'an optimal ECDIS training environment'. This course as presented in the related documents is too specificly customised to a particular ECDIS make of a specific manufacturer.

Stating computer operating system in the model course is not necessary. Moreover, such record exclude ECDIS applications written for another OS which is unfair. 'Win 7' and 'Win Server 2003' names of the operational systems should be removed from the table. This shall ensure no indication of a given software manufacturer.

\section{Teaching Aids (A)}

The list should be supplemented with Raster Navigational Charts (RNC): A6 Raster Navigational Chart (RNC) data, various, including permits and updates.

\section{Electronic media (E)}

The part about Electronic media should be deleted in order to prevent unfair competition, because there are also other products on the market. If it remains, it should be renumbered: E1, E2, E3. 


\section{IMO \& regulatory references $(R)$}

The IHO S-61, IHO S-66 and IEC 61174 should be added to IMO \& regulatory references $(\mathrm{R})$.

\section{Textbooks (T)}

The textbook references should be corrected and updated:

Weintrit A. (2009) The Electronic Chart Display and Information System (ECDIS): An Operational Handbook (Gdynia Maritime University, Poland). A Balkema Book, CRC Press, Taylor \& Francis Group.

\section{Part B: Course Outline and Timetable}

\section{Course Outline - Total 40.0 hours minimum}

The ECDIS Course should be organized in 12 subject areas presented with full details in more than a thousand page handbook T2 [11]:

1. Legal aspects, requirements and international standards.

2. Principal types of ECS and electronic charts.

3. ECDIS data.

4. Presentation of ENC/SENC data.

5. Main functions of ECDIS.

6. Route planning and special functions.

7. Route monitoring and special functions.

8. Data updating system.

9. Additional navigation-related information sensors, display and functions.

10. Voyage data recording (documentation).

11. Errors, status indications, warnings and alarms.

12. Operational requirements.

With $10 \mathrm{Hrs}$ Lectures, $10 \mathrm{Hrs}$ [5 Hrs] Demonstrations, and $20 \mathrm{Hrs}$ [25 Hrs] Practical exercices, and extra $1 \mathrm{Hr}$ [2 Hrs] for Exam.

There is the need for joint topics evaluation, not necessary for precisely 40 separate topics organized in $40 \mathrm{hrs}$ set out in the document STW 43/3/1.

The main function of ECDIS, mentioned in ECDIS definition, is route planning and route monitoring. Route monitoring - area to be extended, Back up arrangements - to be added, Setting of Own Ship's Safety Values and Emergency situations - to be trained. 


\section{WHAT ARE THE REQUIREMENTS FOR ECDIS TYPE SPECIFIC MODEL COURSE?}

IMO Model Course 1.27 gives guidelines for the generic training only but what about the type specific training. Can the IMO 1.27 based course be considered type specific also and a second cert issued for the type specific training?

If the IMO Model Course 1.27 training is conducted in full on the specific make and model of ECDIS it can be considered type specific provided that the training conducted is endorsed by the manufacturer.

There is plenty of reference regarding the 'type specific' training. But, it is very difficult to find anything on how this can be done. Maybe one solution is to attend the Course and another is to train the crew onboard the vessel, taking in account manufacture's manual, compile a checklist? And why should they be 'certified'?

The certificate is the only way for a vetting officer to visually verify that the individual navigator is qualified for the position he/she is holding. Then the inspection will allow for verification that the certificate is not only a piece of paper but that it is supported by firm knowledge by the holder of the certificate.

Again, it is up to the individual manufacturer to decide how they want the proof of comptence to be visualized. Finally, the certificate may, just as a confined waters pilot license or a chem-tanker certificate, contribute to strengthen the individual navigators position when applying for a job with a new company.

The type specific training requirements depend very much on the flag of the ships are flying, so the question can only be ansered for each flag separately. Unfortunately so far not all flag states have issued clear guidance on how they expect type specific training to be conducted.

British Maritime and Costguard Agency (MCA) for example issued the Marine Information Notice MIN $405 \mathrm{M}+\mathrm{F}$ (http://www.dft.gov.uk/mca/min_405.pdf), which clarifies the equipment specific training:

This training should build on the MCA approved ECDIS generic training, and be delivered by the manufacturer; the manufactures approved agent or a trainer who has attended such a programme. Trickle down training (i.e. one officer training another) is not acceptable as, inevitably, it leads to incomplete knowledge of the equipments capabilities, and especially the lesser used functions, being passed on.

That means that for the UK flag it is not sufficient to attend a type specific training and train the officers, you would need a manufacturer train-the-trainer course and the approval of the manufacturer for your internal courses in order to become a approved agent. 
If shipowner want to train his crew on-board he should also keep in mind that according to the ISM Code the familiarization should be completed before the officer takes over his duties and that developing the courseware for a high quality training on your own will be a lot of work even if you just have one or two different ECDIS systems installed throughout your fleet. Not regarding keeping pace with updated software versions new regulations.

A manufacturers train-the-trainer course for a specific product does not necessarily include lessons on didactics and basic teaching skills as being covered by IMO Model Course 6.09 'Training Course for Instructors'. The manufacturers trainer course should cover the system in more detail compared to the normal type specific training in order to enable the trainer to answer upcoming questions and have a deep knowledge of the system. Unfortunatelly, not all manufactueres offer dedicated courses but all of them should be able to provide navigators with such a training on request.

Also small brands have the possibility to join a training network or establish cooperations with independant training institutes to provide high quality training. So there should be no excuse on not being able to provide training. In the end it is up to the specific ECDIS brand what they judge as appropriate training for the trainers. Eventually they might as well have an easier solution for training needs which they can provide with.

\section{CONCLUSIONS}

While there are about 50 manufacturers of ECDIS at present, generic training should provide the navigator with the basics to enable them to use the rquipment to navigate on any system, to become familiar with the international requirements and standards, and to understand the limitations of the system.

The new IMO Model course 1.27, the contents of which were finalized at the resent STW sub-committee at IMO, is much more prescriptive in its content than the previous version.

\section{REFERENCES}

[1] Gale H., ECDIS - mandatory carriage begins. Seaways, The International Journal of The Nautical Institute, July 2012, pp. 21-23. 
[2] IMO STCW, 1995: The International Convention on Standards of Training, Certification and Watchkeeping for Seafarers (or STCW), International Maritime Organization, 1995.

[3] IMO STCW, 2010: The International Convention on Standards of Training, Certification and Watchkeeping for Seafarers 1995 with Manila Amendments 2010, International Maritime Organization, 2010.

[4] IMO Model Course 1.27, 2000: The Operational Use of Electronic Chart Display and Information Systems (ECDIS), Maritime Organization, London, October 2000 .

[5] IMO STW 31/3, 1999: Validation of Model Training Course Content, Draft IMO Model Course for The Operational Use of Electronic Chart Display and Information Systems (ECDIS), Submitted by Poland, International Maritime Organization, London, October 1999 (Chairman of The Working Group: Weintrit A.).

[6] IMO STW 32/9, 2000: Development of Guidance on Training in the Use of ECDIS, Draft of a Guidance on Training and Assessment in the Operational Use of the Electronic Chart Display and Information Systems (ECDIS), Submitted by Poland, International Maritime Organization, London, 3 October 2000 (Authors: Weintrit A., Ferlas Z.).

[7] IMO STW 32/WP.7, 2001: Development of Guidance on Training in the Use of ECDIS, Report of Drafting Group under the chairmanship of Mr. A. Weintrit (Poland), Interim Guidance on Training Use of The Electronic Chart display and Information Systems (ECDIS) Simulators, International Maritime Organization, London, 25 January 2001.

[8] IMO STCW.7/Circ.10, 2001: Interim Guidance on Training and Assessment in the Operational Use of the Electronic Chart Display and Information System (ECDIS) Simulators, International Maritime Organization, London 2001 (under chairmanship of Mr. A.Weintrit).

[9] IMO STW 43/3/1, 2012: Validation of Model Training Courses. Model Course - Operational Use of the Electronic Chart Display and Information Systems (ECDIS), Submitted by Secretariat, International Maritime Organization, London, 4 May 2012 with Annex IMO Model Course 1.27: on the operational use of Electronic Chart Display and Information Systems (ECDIS), 2010 edition, developed by the United States Merchant Marine Academy, Kings Point, New York.

[10] IMO STW 43/3/19, 2012: Validation of Model Training Courses. Model Course - Operational Use of the Electronic Chart Display and Information Systems (ECDIS), Submitted by Poland. International Maritime Organization, London, 9 March 2012 (Authors: Weintrit A., Kopacz P., Bąk A., Uriasz J., Naus K.). 
[11] Weintrit A., 2009: The Electronic Chart Display and Information System (ECDIS), An Operational Handbook, A Balkema Book, CRC Press, Taylor \& Francis Group, Boca Raton - London - New York - Leiden, p. 1101.

[12] www.furuno.com/en/business_product/merchant/product/ecdis_fmd/carriage/in dex.html (12.04.2012).

Received May 2012

Reviewed October 2012 